\title{
The Use of Mechanical Insufflation-Exsufflation Via Artificial Airways
}

During the past 20 years, airway clearance techniques have been the subject of increasing scientific interest. Cough augmentation with mechanical insufflation-exsufflation is part of this trend. No fewer than 23 studies, of which 21 were published in the past 10 years, have improved the level of evidence on this technique. ${ }^{1-23}$ As suggested in Figure 1, the availability of insufflation-exsufflation in Europe since 2002 has increased the number of studies in this field. The addition of knowledge on insufflation-exsufflation recently accelerated, as evidenced by 10 original studies published during the last 4 years. ${ }^{14-23}$

The particularity of insufflation-exsufflation is that it provides a mechanical assistance to compensate for deficits in both the inspiratory and expulsive phase of cough in patients with low respiratory muscle strength. Often associated with noninvasive mechanical ventilation, ${ }^{1,19,22}$ insufflation-exsufflation is used in adults, children, and even infants. $^{22}$ To my knowledge, 3 insufflation-exsufflation devices are available on the market: CoughAssist (Philips Respironics, Murrysville, Pennsylvania); Pegaso (Dima Italia, Bologna, Italia); and Clearway (B\&D Electromedical, Warwickshire, United Kingdom). To date, the efficacy, safety, and tolerance of insufflation-exsufflation have been investigated in patients with only one of these 3 devices, the CoughAssist.

We must remember that an insufflation-exsufflation device that uses a noninvasive mask does not create a cough ex nihilo. Indeed, assisted cough requires the active participation of the patient who, although very weak, must perform a cough maneuver that includes glottal closure. In this case, weak but existing cough is amplified by the insufflation-exsufflation device. In contrast, when insufflation-exsufflation is used with an invasive interface, the cough maneuver is not essential. The insufflation-exsufflation device can create an artificial cough, even in unconscious, sedated patients.

\section{Insufflation-Exsufflation via Noninvasive Interface: Cough is Amplified}

As previously mentioned, the use of insufflation-exsufflation via noninvasive interface requires the patient's active participation. The device acts as an amplifier of the ineffective spontaneous cough. At least partial glottal clo- sure is required before the expulsive phase of the cough. In the total absence of glottal control, insufflation-exsufflation is ineffective. ${ }^{8}$

See the Original Study on Page 1108

In very weak patients with restrictive respiratory syndromes and upper airway encumbrance, but not in patients with obstructive respiratory syndromes, the capacity of the insufflation-exsufflation device to produce expiratory cough flows at a higher rate than any manual or instrumental cough augmentation technique is well documented.1,2,5,20 In addition, insufflation-exsufflation may prevent hospitalizations ${ }^{18,19}$ and avoid the need for tracheostomy or intubation. ${ }^{12}$ It reduces dyspnea, ${ }^{11}$ shortens upper-airway-clearance sessions, ${ }^{16}$ and stabilizes or improves blood gases. ${ }^{11,14,16}$ The level of evidence on the effectiveness of insufflation-exsufflation is considered sufficient to recommend its use in very weak patients with ineffective cough. ${ }^{24} \mathrm{~A}$ large number of patients from occidental countries may benefit from insufflation-exsufflation, provided they have major, explicit, and proven cough deficit. However, the high price of insufflation-exsufflation devices deprives countries with limited financial resources of this technique.

\section{Insufflation-Exsufflation via Invasive Interface: Coughing is Simulated}

Despite promising results, ${ }^{6,13}$ the use of insufflationexsufflation in invasive conditions is not yet common. In the presence of an invasive interface, using insufflationexsufflation is possible via an adapter to an endotracheal or tracheostomy tube (Fig. 2). In this case, neither the patient's spontaneous coughing nor glottis control is necessary, because the pressures generated by the insufflation-exsufflation device are directly applied into the trachea (ie, the subglottic area).

By contrast to the use of insufflation-exsufflation with a noninvasive interface, the production of high expiratory flow through an artificial airways is totally independent of the patient's effort. As suggested in Figure 2, it is convenient to superficially introduce a suction catheter into the cannula through the tracheal adapter. Ideally, the catheter 


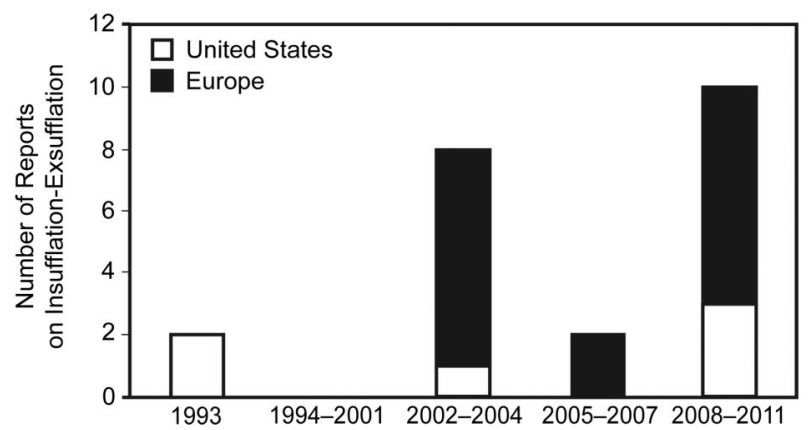

Fig. 1. History of studies on mechanical in-exsufflation.

will not extend beyond the tube, to avoid any contact with the tracheal mucosa. This precaution may avoid granuloma, bleeding, and irritation of mucous membranes. ${ }^{25}$ Prolonged use is possible in unconscious patients under ventilatory support, because the inspiratory positive pressure during insufflation can provide rudimentary ventilatory support.

In recent studies, the CoughAssist was applied to tracheotomized patients with spinal cord injury ${ }^{3,13}$ or neuromuscular disease.6,9 Insufflation-exsufflation was compared to endotracheal suctioning on a cannula with inflated cuff. ${ }^{6}$ Patients found the CoughAssist more effective, less irritating, less painful, less tiring, and more comfortable and convenient than suctioning. ${ }^{3,6}$ To date, however, adequate insufflation-exsufflation settings for artificial airways are not well known.

We know that increasing the inspiratory or expiratory time does not affect the maximum expiratory flow during exsufflation, whereas increasing the inspiratory and/or expiratory pressure increases the maximum expiratory flow. ${ }^{21}$ In the current issue of RespiRatory CARE, Guérin et al ${ }^{23}$ report an in vitro study of insufflation-exsufflation with the CoughAssist, with several sizes of endotracheal and tracheostomy tube, and with several lung model compliance and resistance settings. Their study did not aim at showing any evidence on the effectiveness of insufflationexsufflation technology, but at measuring the impact of artificial airways on expiratory flows and volumes. As expected, the artificial airways significantly reduced the maximum expiratory flow during insufflation-exsufflation with the CoughAssist. For a given expiratory pressure, the narrowest internal diameter of artificial airway corresponded to the lowest peak expiratory flow. However, Guérin et al suggest future studies to confirm these in vitro observations in in vivo conditions. The additional finding that an increase in airway resistance or decrease in thoraco-pulmonary compliance decreased the expiratory cough flow is consistent with previous findings by Sancho and co-workers. ${ }^{10}$ Interestingly, Table 5 from Guérin et al ${ }^{23}$ suggests the pressures necessary to generate effective assisted expiratory flows under various conditions of resis-

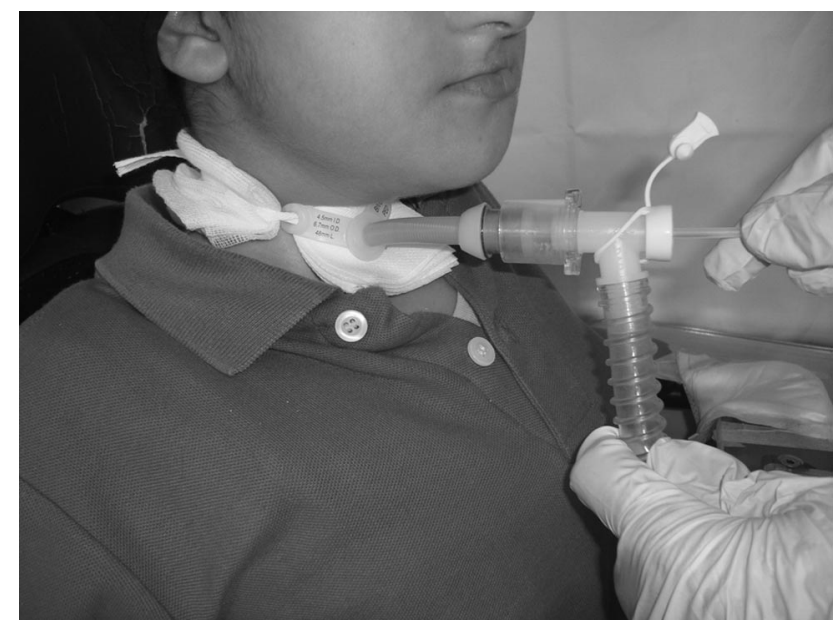

Fig. 2. Suctioning during a mechanical insufflation-exsufflation treatment via a tracheal adapter.

tance and compliance as a function of artificial airway tube diameter. These data are relevant for clinicians because they provide a tool that is immediately useful in clinical practice in the intensive care unit.

My impression is that the use of insufflation-exsufflation in the coming years will increase in patients ventilated via artificial airways and presenting major difficulties for airway clearance in the intensive care unit. The interest of the study by Guérin et $\mathrm{al}^{23}$ is that they controlled the experimental conditions of their in vitro investigation, such as airway resistance and thoraco-pulmonary compliance.

Whatever insufflation-exsufflation is used via invasive or noninvasive interface, the time has come to "fine tune" insufflation-exsufflation indications and settings depending on the patient's characteristics rather than to further demonstrate insufflation-exsufflation effectiveness. The study by Guérin et $\mathrm{al}^{23}$ illustrates well these new targets.

Michel Toussaint PhD

Acute Neurorespiratory Rehabilitation Unit Neuromuscular Excellency Centre Vrije Universiteit Brussel - Inkendaal and

Centre for Home Mechanical Ventilation Ziekenhuis Inkendaal Rehabilitation Hospital Brussels, Belgium

\section{REFERENCES}

1. Bach JR, Smith WH, Michaels J, Saporito L, Alba AS, Dayal R, Pan J. Airway secretion clearance by mechanical exsufflation for postpoliomyelitis ventilator-assisted individuals. Arch Phys Med Rehabil 1993;74(2):170-177.

2. Bach JR. Mechanical insufflation-exsufflation. Comparison of peak expiratory flows with manually assisted and unassisted coughing techniques. Chest 1993;104(5):1553-1562. 


\section{The Use of Mechanical Insufflation-Exsufflation Via Artificial Airways}

3. Garstang SV, Kirshblum SC, Wood KE. Patient preference for inexsufflation for secretion management with spinal cord injury. J Spinal Cord Med 2000;23(2):80-85.

4. Gómez-Merino E, Sancho J, Marín J, Servera E, Blasco ML, Belda FJ, et al. Mechanical insufflation-exsufflation: pressure, volume, and flow relationships and the adequacy of the manufacturer's guidelines. Am J Phys Med Rehabil 2002;81(8):579-583.

5. Chatwin M, Ross E, Hart N, Nickol AH, Polkey MI, Simonds AK. Cough augmentation with mechanical insufflation/exsufflation in patients with neuromuscular weakness. Eur Respir J 2003;21(3):502508.

6. Sancho J, Servera E, Vergara P, Marín J. Mechanical insufflationexsufflation vs. tracheal suctioning via tracheostomy tubes for patients with amyotrophic lateral sclerosis: a pilot study. Am J Phys Med Rehabil 2003;82(10):750-753.

7. Mustfa N, Aiello M, Lyall RA, Nikoletou D, Olivieri D, Leigh PN, et al. Cough augmentation in amyotrophic lateral sclerosis. Neurology 2003;61(9):1285-1287.

8. Sancho J, Servera E, Díaz J, Marín J. Efficacy of mechanical insufflation-exsufflation in medically stable patients with amyotrophic lateral sclerosis. Chest 2004;125(4):1400-1405.

9. Miske LJ, Hickey EM, Kolb SM, Weiner DJ, Panitch HB. Use of the mechanical in-exsufflator in pediatric patients with neuromuscular disease and impaired cough. Chest 2004;125(4):1406-1412.

10. Sancho J, Servera E, Marín J, Vergara P, Belda FJ, Bach JR. Effect of lung mechanics on mechanically assisted flows and volumes. Am J Phys Med Rehabil 2004;83(9):698-703.

11. Winck JC, Gonçalves MR, Lourenço C, Viana P, Almeida J, Bach JR. Effects of mechanical insufflation-exsufflation on respiratory parameters for patients with chronic airway secretion encumbrance. Chest 2004;126(3):774-780.

12. Vianello A, Corrado A, Arcaro G, Gallan F, Ori C, Minuzzo M, Bevilacqua M. Mechanical insufflation-exsufflation improves outcomes for neuromuscular disease patients with respiratory tract infections. Am J Phys Med Rehabil 2005;84(2):83-88.

13. Pillastrini P, Bordini S, Bazzocchi G, Belloni G, Menarini M. Study of the effectiveness of bronchial clearance in subjects with upper

The author has disclosed no conflicts of interest.

Correspondence: Michel Toussaint PhD, Ziekenhuis Inkendaal Rehabilitation Hospital, Inkendaalstraat 1, 1602 Vlezenbeek, Belgium, Brussels. E-mail: michel.toussaint@inkendaal.be.

DOI: $10.4187 /$ respcare. 01448 spinal cord injuries: examination of a rehabilitation programme involving mechanical insufflation and exsufflation. Spinal Cord 2006; 44(10):614-616.

14. Fauroux B, Guillemot N, Aubertin G, Nathan N, Labit A, Clément A, Lofaso F. Physiologic benefits of mechanical insufflation-exsufflation in children with neuromuscular diseases. Chest 2008;133(1): 161-168.

15. Suri P, Burns SP, Bach JR. Pneumothorax associated with mechanical insufflation-exsufflation and related factors. Am J Phys Med Rehabil 2008;87(11):951-955.

16. Chatwin M, Simonds AK. The addition of mechanical insufflation/ exsufflation shortens airway-clearance sessions in neuromuscular patients with chest infection. Respir Care 2009;54(11):1473-1479.

17. Crew JD, Svircev JN, Burns SP. Mechanical insufflation-exsufflation device prescription for outpatients with tetraplegia. J Spinal Cord Med 2010;33(2):128-134.

18. Bento J, Gonçalves M, Silva N, Pinto T, Marinho A, Winck JC. Indications and compliance of home mechanical insufflation-exsufflation in patients with neuromuscular diseases Arch Bronconeumol 2010;46(8):420-425.

19. Vitacca M, Paneroni M, Trainini D, Bianchi L, Assoni G, Saleri M, et al. At home and on demand mechanical cough assistance program for patients with amyotrophic lateral sclerosis. Am J Phys Med Rehabil 2010;89(5):401-406.

20. Senent C, Golmard JL, Salachas F, Chiner E, Morelot-Panzini C, Meninger $\mathrm{V}$, et al. A comparison of assisted cough techniques in stable patients with severe respiratory insufficiency due to amyotrophic lateral sclerosis. Amyotroph Lateral Scler 2011;12(1):26-32.

21. Striegl AM, Redding GJ, Diblasi R, Crotwell D, Salyer J, Carter ER. Use of a lung model to assess mechanical in-exsufflator therapy in infants with tracheostomy. Pediatr Pulmonol 2011;46(3):211-217.

22. Chatwin M, Bush A, Simonds AK. Outcome of goal-directed noninvasive ventilation and mechanical insufflation/exsufflation in spinal muscular atrophy type I. Arch Dis Child 2011;96(5):426-432.

23. Guérin C, Bourdin G, Leray V, Delannoy B, Bayle F, Germain M, Richard J-C. Performance of the CoughAssist insufflation-exsufflation device in the presence of an endotracheal tube or tracheostomy tube: a bench study. Respir Care 2011;56(8):1108-1114.

24. Rosière J, Vader JP, Cavin MS, Grant K, Larcinese A, Voellinger R, Burnand B, Revelly JP, Fitting JW. Appropriateness of respiratory care: evidence-based guidelines. Swiss Med Wkly 2009;139(27-28): 387-392.

25. Soudon P, Steens M, Toussaint M. A comparison of invasive versus noninvasive full-time ventilation in Duchenne muscular dystrophy. Chron Respir Dis 2008;5(2):87-93. 